\title{
ЭВОЛЮЦИЯ ФОРМ ЕВРАЗИЙСКОЙ ИНТЕГРАЦИИ: МЕХАНИЗМ ВЗАИМОДЕЙСТВИЯ ГОСУДАРСТВ-ЧЛЕНОВ ЕВРАЗИЙСКОГО ЭКОНОМИЧЕСКОГО СОЮЗА НА ОБЩЕМ РЫНКЕ ГАЗА
}

\author{
(c) 2020 Аллаярова Неля Исмаиловна \\ аспирант кафедры международных экономических отношений \\ Российская таможенная академия, Россия, Люберцы \\ E-mail: nelia.raimzhanova@gmail.com
}

В статье рассматривается ряд вопросов, связанных с анализом интеграционных процессов стран ЕАЭС, роль газовой промышленности в углублении евразийской интеграции. Речь, в частности идет о преимущественно позитивном воздействии региональной экономической интеграции на экономику стран ЕАЭС; о прямой зависимости позитивных эффектов от создания общего рынка газа стран-членов ЕАЭС. Углубление интеграционных связей повышает эффективность энергоснабжения, энергетическую безопасность, и таким образом, экономическую стабильность стран ЕАЭС. В этой связи освещается круг проблем, обусловленных формированием общего газового рынка ЕАЭС. Важное значение для развития общего рынка газа имеет процесс формирования цен на газ.

Ключевые слова: Евразийский экономический союз; ЕАЭС; общий рынок газа; газ; интеграция; региональная интеграция; экономическое развитие.

\section{Введение}

XXI век характеризуется глобализацией региональных газовых рынков, влияющих на развитие мировой экономики и развиваясь по сценарию интеграции нефтяных рынков, но с определенным запаздыванием. Интеграционные процессы в различных регионах мира едины по своему характеру. Интеграция как процесс подразумевает меры, призванные устранить дискриминацию между хозяйственными единицами, относящимися к различным государствам, иначе говоря, отсутствие различных форм дискриминации между национальными хозяйствами. Новая энергетическая доктрина со свободным ценообразованием, высокой конкуренцией на всех стадиях производства энергоносителей и высокой ликвидностью рынков свидетельствует о готовности и зрелости мировой газовой отрасли к глубоким интеграционным процессам.

Экономическая интеграция на глобальном, региональном и субрегиональном уровнях рассматривается как важная инициатива для достижения экономического роста и развития, а формирование Евразийского экономического союза (ЕАЭС, Союз) рассматривается как шаг к более эффективному экономическому росту и успеху среди постсоветских государств [5].

Значение ЕАЭС в глобальном геополитическом и экономическом ландшафте привлекло огромное внимание среди политиков, прави- тельств и академиков, так и бизнес-структур. Большинство из них критически относятся к заявленным целям и задачам ЕАЭС, на самом деле он функционирует и стремится к дальнейшему расширению в ближайшей перспективе. Однако исследования перспектив и вызовов развития ЕАЭС носят весьма ограниченный характер [5].

В рамках интеграционного блока этапы формирования экономического союза можно охарактеризовать как образец классической интеграции, которая сопровождается пошаговыми процессами углубления взаимодействия стран - от свободной торговли к общим рынкам товаров, услуг, капитала и рабочей силы, включая трансформацию экономического блока путем создания новых форм интеграционного сотрудничества между странами ЕАЭС. При этом, формируются общие цели, общие задачи, совместно разрабатываются программы, концепции, комплексы основных мер и страны-участницы заключают соответствующие соглашения и договора, обязуясь активно взаимодействовать в их эффективной реализации.

Углубление ЕАЭС в аспекте создания общего рынка природного газа подразумевает гармонизацию законодательств стран-членов ЕАЭС, разработку новых оптимальных рыночных структур и соответствующих правил поведения на газовом рынке и в целом на энергетическом рынке. Конкретно, с вступлением в силу Дого- 
вора о Евразийском экономическом союзе (Договор), в интеграционном процессе происходит поэтапное объединение национальных газовых рынков пяти стран-участниц Союза [1].

Полномасштабный формат функционирования общего рынка газа ЕАЭС запланирован с 1 января 2025 г. С учетом реальной оценки, складывающейся в странах ЕАЭС энергетической ситуации, формирование общего рынка газа является непременным условием обеспечения энергетической безопасности и действительно устойчивого развития энергетики не только в России, но и в других странах ЕАЭС. В настоящее время и до вступления в силу Международного договора об общем рынке газа ЕАЭС применяются двусторонние соглашения, заключенные между государствами-участниками Союза в отношении поставок газа, если страны-участницы не договорятся об ином.

Вопрос в том, в каком ключе должно идти формирование общего энергетического пространства, какие должны быть стратегические приоритеты, каковы будут принципы системы взаимоотношений, выгодных всем участникам Союза. Известно, что формирование такого сложного механизма основывается на поэтапном подходе.

Цель настоящей статьи - дать представление о позитивных аспектах углубления евразийской экономической интеграции, так и о некоторых тенденциях, препятствующих формированию общего рынка газа ЕАЭС.

\section{Эволюция интеграционных процессов на постсоветском пространстве}

С начала распада интегрированных систем советской энергетики прошло более 25 лет. Срок немалый. Можно говорить об определенных сдвигах в энергетике. Однако проблем и противоречий накопилось множество.

Потеря единого экономического пространства, дезинтеграция экономических связей, региональные конфликты привели к резкому снижению экономических показателей стран СНГ. Наиболее существенный спад экономики пришелся на 1992-1994 гг., в 1995 и 1996 гг. наметилась стабилизация ВВП, а по отдельным странам СНГ - некоторый рост [4]. Здесь можно согласиться с мнением Пьянова С.А., что дезинтеграционный процесс может носить и позитивный характер, движением вперед к более высо- ким ступеням экономического развития, о чем свидетельствовали некоторые интеграционные тенденции на ранних этапах [9], которые приведены в табл.1.

Процесс эволюции постсоветской интеграции обусловлен главной целью - укрепление связей, формирование открытой рыночной экономической системы, в рамках которой возможно функционирование стабильных цен, осуществляя экономический рост, экономическое и социальное выравнивание [7].

Механизм формирования экономической интеграции стран ЕАЭС отличается разноуровневым и разноскоростным характером, с различными востребованными форматами «зоной свободной торговли (ЗСТ)», «Союзным государством России и Беларуси (СРБ)», «Евразийском экономическим сообществом (ЕврАзЭС)», «Таможенным союзом (ТС)», Единым экономическим пространством (ЕЭП), «Евразийским экономическим союзом (ЕАЭС)». Вместе с тем, анализируя опыт постсоветских республик в развитии интеграционных процессов, можно отметить, что СНГ как первый интеграционный проект постсоветских стран выступил в наибольшей степени возможностью «смягчения» процесса распада СССР на 15 независимых государств, позволил сделать размежевание республик менее кризисным и конфликтным для стран-участниц [9]. Однако распад этой системы, в свою очередь, стал одним из факторов дестабилизации энергообеспечения в большинстве постсоветских республик. Сокращение производства топливно-энергетических ресурсов в России и других странах СНГ негативно сказалось на экономике, а несогласованная ценовая, налоговая политика привела к ухудшению экономических связей внутри Содружества [4]. В ряде стран наблюдалась излишняя ориентация на третьи страны в развитии своих энергосистем в ущерб использованию своей энергетической инфраструктуры.

Необходимо понимать, что результаты развития интеграции в рамках СНГ оказались противоречивыми: достигнув огромного количества договоренностей, страны так и не сумели восстановить взаимовыгодное партнерство, большинство обязательств остались не реализованными [9].

Важно подчеркнуть, что наиболее успешным примером региональной экономической ин- 
теграции между странами постсоветского пространства следует считать формирование ЕАЭС, который предполагает совершенствование трансграничной инфраструктуры и укрепление институциональных механизмов в рамках приоритетов обеспечения экономической и энергетической безопасности стран-участниц Союза, создавая новые возможности взаимодействия, в частности упразднение внутренних барьеров для торговли в рамках Союза, а также обеспечение свободного перемещения товаров, услуг, трудовых ресурсов и капитала.
Особенностью евразийской интеграции является ее институциональный характер, т.е. процесс интеграции происходит в условиях ведущей роли государств и правительств, создающих влиятельные межгосударственные институты с исполнительно-координационными функциями. Органами управления ЕАЭС являются Высший евразийский экономический совет (ВЕЭС) и Евразийская экономическая комиссия (ЕЭК). ВЕЭС является высшим наднациональным органом ЕАЭС, в составе которого все лидеры государств и главы правительств.

\section{Таблица 1. Этапы постсоветской интеграции}

\begin{tabular}{|c|c|c|}
\hline Дата, документ & Формы интеграции & Страны-участники \\
\hline $\begin{array}{l}\text { Соглашение стран СНГ от } \\
15.04 .1994 \text { «О создании зоны сво- } \\
\text { бодной торговли» }\end{array}$ & Зона свободной торговли СНГ & $\begin{array}{l}\text { Азербайджан, Армения, Белорус- } \\
\text { сия, Грузия, Казахстан, Киргизия, } \\
\text { Молдавия, Россия, Таджикистан, } \\
\text { Туркмения, Узбекистан, Украина }\end{array}$ \\
\hline $\begin{array}{l}\text { «Соглашение о Таможенном союзе } \\
\text { между Российской Федерацией и } \\
\text { Республикой Беларусь» (заключено } \\
\text { в г. Минске 06.01.1995) }\end{array}$ & Таможенный союз & Россия, Белоруссия \\
\hline $\begin{array}{l}\text { «Договор об учреждении Евразий- } \\
\text { ского экономического сообщества» } \\
\text { (подписан в г. Астане } 10.10 .2000)\end{array}$ & $\begin{array}{l}\text { Евразийское экономическое сооб- } \\
\text { щество (ЕвраАзЭС) }\end{array}$ & $\begin{array}{l}\text { 2001-2014 - Белоруссия, Казахстан, } \\
\text { Киргизия, Россия; } \\
\text { 2006-2008 - Узбекистан (приоста- } \\
\text { новлено членство) } \\
\text { Гос-ва-наблюдатели: } \\
\text { 2002-2014 - Молдавия, Украина; } \\
\text { 2003-2014 - Армения }\end{array}$ \\
\hline $\begin{array}{l}\text { “Договор о создании единой тамо- } \\
\text { женной территории и формирова- } \\
\text { нии Таможенного союза” (подпи- } \\
\text { сан в г. Душанбе 06.10.2007) }\end{array}$ & $\begin{array}{l}\text { Таможенный союз - свобода дви- } \\
\text { жения товаров: } \\
\text { - единый таможенный кодекс } \\
\text { - единый таможенный тариф } \\
\text { - единая система тарифного регу- } \\
\text { лирования и нетарифного регули- } \\
\text { рования }\end{array}$ & Россия, Казахстан, Белоруссия \\
\hline $\begin{array}{l}\text { Соглашение о формировании ЕЭП } \\
\text { (подписано 19.09.2003 в г. Ялте) } \\
\text { Переговоры с 1995-2011 гг. } \\
\text { Вступление с 01.01.2012 г. }\end{array}$ & $\begin{array}{l}\text { Единое экономическое простран- } \\
\text { ство (общий рынок): } \\
\text { - свобода движения капитала, } \\
\text { услуг, рабочей силы } \\
\text { - } 17 \text { базовых соглашений } \\
\text { - учреждение ЕЭК } \\
\text { - функционирование по програм- } \\
\text { мам ВТО }\end{array}$ & $\begin{array}{l}\text { с 29.05.2012 - Белоруссия, Казах- } \\
\text { стан, Россия; } \\
\text { с 10.10.2014 - Армения; } \\
\text { с 23.05.2015 - Киргизия }\end{array}$ \\
\hline $\begin{array}{l}\text { “Договор о Евразийском экономи- } \\
\text { ческом союзе” (подписан в г. Аста- } \\
\text { не 29.05.2014. Ратифицирован } \\
\text { Федеральным законом } \\
\text { от 03.10.2014 } \\
\text { N279-Ф3) }\end{array}$ & $\begin{array}{l}\text { Евразийский экономический союз: } \\
\text { - углубление интеграции } \\
\text { - ликвидация изъятий на пути } \\
\text { реализации «четырех свобод» } \\
2015 \text { г.: экономический союз с } \\
\text { международной правосубъектно- } \\
\text { стью и соответствующими инсти- } \\
\text { тутами } \\
\text { - «четыре свободы»- товары, } \\
\text { услуги, капиталы, рабочая сила } \\
\text { - согласованные политики по } \\
\text { секторам экономики } \\
\text { - общая инфраструктура }\end{array}$ & $\begin{array}{l}\text { Государства-члены: } \\
\text { с 01.01.2015 - Белоруссия, Казах- } \\
\text { стан, Россия; } \\
\text { с 02.012015 - Армения; } \\
\text { с 12.08.2015 - Киргизия } \\
\text { Государства-наблюдатели: } \\
\text { Молдавия (с 14.05.2018) } \\
\text { Зона свободной торговли: } \\
\text { Вьетнам, Иран, Сингапур, Сербия }\end{array}$ \\
\hline
\end{tabular}




\begin{tabular}{|c|c|c|}
\hline \multicolumn{3}{|c|}{ Углубление евразийской интеграции в рамках ЕАЭС } \\
\hline $\begin{array}{l}\text { Начало функционирования рынка } \\
\text { 01.01.2016 г. }\end{array}$ & $\begin{array}{l}\text { Общий рынок лекарственных } \\
\text { средств и медицинских изделий }\end{array}$ & \\
\hline $\begin{array}{l}\text { Запуск рынка не позднее } \\
01.01 .2025 \text { г. }\end{array}$ & $\begin{array}{l}\text { Общий электроэнергетический } \\
\text { рынок }\end{array}$ & $\begin{array}{l}\text { Концепция формирования общего } \\
\text { электроэнергетического рынка } \\
\text { Программа формирования общего } \\
\text { электроэнергетического рынка } \\
\text { Методология формирования инди- } \\
\text { кативных (прогнозных) балансов } \\
\text { газа, нефти, нефтепродуктов } \\
\text { Международный договор о форми- } \\
\text { ровании общего электроэнергети- } \\
\text { ческого рынка }\end{array}$ \\
\hline 01.01.2016 г. & $\begin{array}{l}\text { Единое экономическое простран- } \\
\text { ство }\end{array}$ & $\begin{array}{l}\text { Функционирует: } \\
\text { - свободное движение товаров и } \\
\text { услуг } \\
\text { - свободное движение капитала } \\
\text { - свободное движение рабочей } \\
\text { силы }\end{array}$ \\
\hline $\begin{array}{l}\text { Запуск рынка не позднее } \\
01.01 .2025 \text { г. }\end{array}$ & $\begin{array}{l}\text { Общие рынки нефти и нефтепро- } \\
\text { дуктов }\end{array}$ & $\begin{array}{l}\text { Концепция формирования общих } \\
\text { рынков нефти и нефтепродуктов } \\
\text { Программа формирования общих } \\
\text { рынков нефти и нефтепродуктов } \\
\text { Международный договор о фор- } \\
\text { мировании общих рынков нефти и } \\
\text { нефтепродуктов }\end{array}$ \\
\hline $\begin{array}{l}\text { Запуск рынка не позднее } \\
01.01 .2025 \text { г. }\end{array}$ & Общий рынок газа & $\begin{array}{l}\text { Концепция формирования общего } \\
\text { рынка газа } \\
\text { Программа формирования общего } \\
\text { рынка газа } \\
\text { Международный договор о форми- } \\
\text { ровании общего рынка газа }\end{array}$ \\
\hline
\end{tabular}

Источник: составлено автором по материалам ЕЭК [12]

Основные институциональные механизмы, действующие в рамках функционирования ЕАЭС идентичны действующим механизмам Европейского союза (ЕС), в силу того, что при создании ЕАЭС был использован международный опыт, и в первую очередь, опыт ЕС. Таким образом, в соответствии с п.1 статьи 18 Договора о ЕАЭС от 29.05.2014 г. ЕЭК является постоянно действующим регулирующим органом ЕАЭС с наднациональными функциями в сфере экономической интеграции в рамках ЕАЭС [1,9].

Сегодня ЕАЭС как международная организация региональной экономической интеграции и субъект международного права - довольно молодое объединение в сравнении с ЕС, однако в 2025 г. будет 10 лет с момента создания (01.01.2015 г.) [3]. 2015 г. для России и Казахстана характеризуется периодом нефтяного шока и рецессии, что не могло не отразиться на экономике других стран-участниц Союза [3]. Несмотря на негативные внешние условия начальный период интеграционных процессов прошел успешно.

Определенную роль в объединении сыграла взаимная торговля стран, объемы которой увеличивались в течение всего 2016 г. и начиная с сентября уже превышали значения соответствующих месяцев прошлого года (рис. 1 график). Развитие взаимной торговли товарами между странами-участницами Союза в 2018 г. определила положительная тенденция, сформировавшаяся в 2016 г. За 2018 г. товарооборот внутри ЕАЭС превысил 44 млрд. долл., прирост составил 11,9\% относительно предыдущего года [11].

Необходимо признать, что экономический потенциал ЕАЭС очень мощный, с точки зрения экономики, Союз объединяет пять государств с общей численностью 183,8 млн. человек и совокупным ВВП, равным 85\% стран СНГ, на его территории, которая составляет более 20 млн. кв. км (14\% мировой суши), сосредоточена пятая часть мировых запасов природного газа. Запасы природного газа в 2018 г. оценивались величиной 34109,0 млрд. куб. м. 


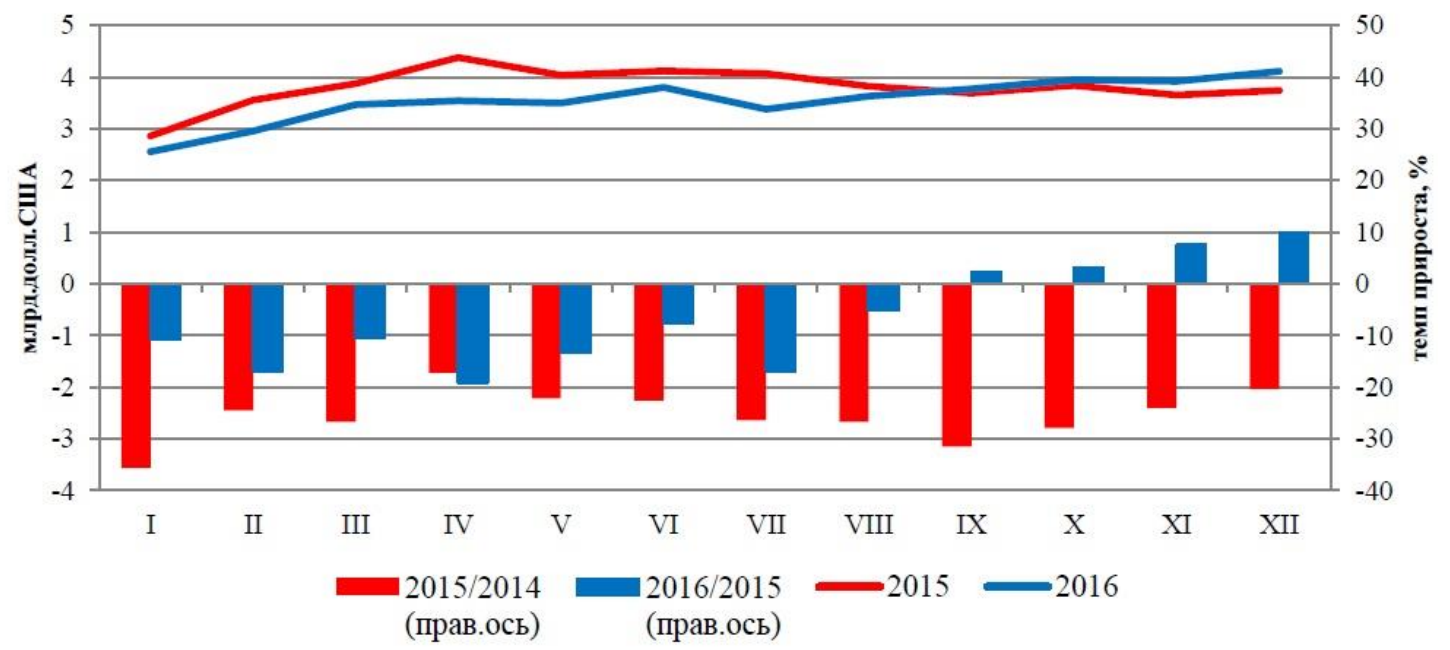

Puc. 1. Объемы взаимной торговли ЕАЭС 2015-2016 гг.

Источник: Доклад «О состоянии взаимной торговли между государствами - членами

Евразийского экономического союза в 2015-2016 годах» [Электронный ресурс] Режим доступа: http://www.eurasiancommission.org/ru/act/integr_i_makroec/dep_stat/tradestat/analytics/Documents/report/Report_2015-2016.pdf

\section{Векторы взаимодействия государств- членов ЕАЭС на общем рынке газа}

Приоритетным направлением в развитии региональных интеграционных процессов на постсоветском пространстве является сфера энергетики, при этом важная роль отводится природному газу, занимающему центральное место в энергообеспечении стран ЕАЭС. Важнейшими направлениями деятельности ЕЭК в данном секторе является содействие проведению согласованной энергетической политики и создание необходимых предпосылок для формирования единых рыночных механизмов в топливно-энергетическом комплексе.

Политика, направленная на повышение роли газа в топливно-энергетическом балансе ЕАЭС, осуществляется путем развития надежной ресурсной базы, мощной ГТС, а также соответствующей газоперерабатывающей промышленности, предприятий по производству труб, оборудования для добычи, транспортировки и распределения газа. Все это способствует увеличению объемов добычи газа в ЕАЭС (табл.2).
Как известно, ЕАЭС занимает лидирующие позиции в мире в части: добычи газа -1 место в мире (20,2\% от мировой доли); добычи нефти - 1 место в мире (14,5\% от мировой доли); и др. В общей добыче газа стран ЕАЭС доля России составляет 95,2\%, Казахстан $-4,6 \%$, и не более $0,2 \%$ доли на остальные страны ЕАЭС. Большая часть энергоресурсов находится на территории Российской Федерации, Казахстан обладает значительными объемами запасов нефти и угля [10].

Суммарное потребление природного газа в 2017 г. странами ЕАЭС оценивалось величиной 36,3 млрд. куб. м. Белоруссия является основным потребителем в ЕАЭС (не учитывая Российскую Федерацию) - 19,7 млрд. куб. м, импорт газа из России составляет $100 \%$ [10].

Суммарный ВВП стран оценивается величиной порядка 2,2 трлн. долл.- около 85\% ВВП всех стран СНГ. В целом ЕАЭС занимает 8-е место в мире по объему промышленного производства. При этом, важно, что на Россию приходится порядка 87\% всего экономического потенциала стран-участниц ЕАЭС.

Таблица 2. Общие показатели газовой отрасли ЕАЭС за период 2016-2018 гг.

\begin{tabular}{|l|c|c|c|}
\hline & \multicolumn{3}{|c|}{ ЕАЭС (млрд. куб. м) } \\
\hline Показатель & 2016 & 2017 & 2018 \\
\hline Запасы газа & 34109,0 & 34109,0 & 34109,0 \\
\hline Добыча газа & 671,9 & 709,9 & 781,1 \\
\hline Экспорт газа (всего) & 210,9 & 241,6 & 241,6 \\
\hline Экспорт газа в третьи страны & 177,4 & 196,3 & 211,5 \\
\hline Внутреннее потребление газа & 519,0 & 537,7 & 518,1 \\
\hline
\end{tabular}


Одной из важнейших задач внутренней энергетической политики ЕАЭС выступает формирование общего газового рынка в евразийском регионе, запуск которого запланирован к 2025 г. В настоящее время на основании Договора о ЕАЭС уже учрежден ряд документов, связанных с формированием общего рынка газа Союза (рис. 2). По окончании реализации мероприятий Программы формирования общего рынка газа, странами ЕАЭС будет утвержден Международный договор о формировании общего газового рынка Союза, содержащий в том числе единые правила доступа к ГТС, расположенным на территориях государств-участников. Вступление данного договора запланировано не позднее 01.01.2025 г. Необходимо отметить, что в рамках данного документа будет определен формат - регулируемая или либеральная интеграция [6]. При этом, одной из сложных задач для подготовки Международного договора является унификация единых правил доступа к услугам естественных монополий [2].

Особенностью формирования общего рынка газа ЕАЭС является система тесных контактов с его главным поставщиком газа со времен б. СССР - Россией. В контексте газовых взаимоотношений, надо отметить, что проект по созданию общего газового рынка ЕАЭС станет успешным, в случае, если страны-участницы смогут преодолеть институциональные различия текущих моделей национальных рынков природного газа и достигнут компромисса в проектировании Целевой модели будущего общего рынка газа ЕАЭС.

Говоря об эволюции газового рынка, необходимо отметить, сложившуюся со времен СССР, специфическую форму - государственный монополизм.

Следует признать, что сформированный за годы социалистического хозяйствования, тип монополизации экономики и имеющий в своей основе несовершенные механизмы реализации общенародной собственности, явился предпосылкой развития современной газовой монополистической структуры [8]. Одной из особенностей газовой отрасли, оказывающих специфическое влияние на развитие рынка газа, является продолжительное доминирование вертикально-интегрированной компании-монопо-

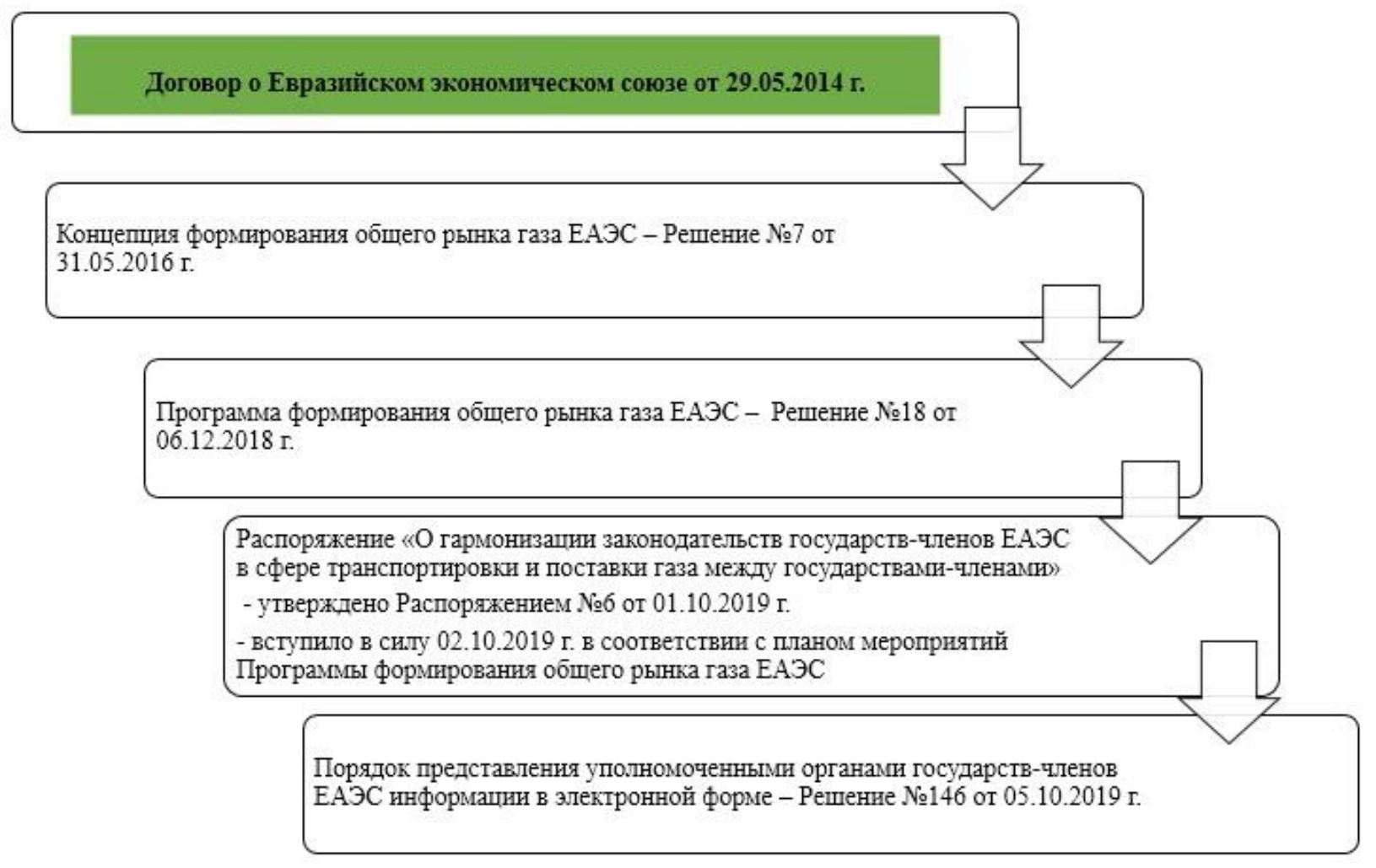

Puc. 2. Актуальные документы общего рынка газа ЕАЭС 
листа - ПАО «Газпром», который играет важную роль в усилении интеграционных связей между странами ЕАЭС и проводящий интеграционную политику на базе ЕСГ.

Сегодня суммарная протяженность ЕСГ России составляет свыше 172 тыс. км, объединяющая газоснабжающие системы Казахстана и Белоруссии, включает в себя сотни разрабатываемых месторождений, разветвленную сеть газопроводов, компрессорные станции и др. сооружения. ЕСГ загружена полностью, суммарное поступление природного газа в ГТС «Газпрома» в 2018 г. составило свыше 638,7 млрд. куб. м. Сохранение целостности ЕСГ является непременным условием достигнутых уровней добычи газа и их последующего наращивания.

Говоря, о различиях национальных рынков газа стран ЕАЭС, следует отметить, что белорусский рынок газа функционирует в рамках системы государственного управления и планирования. Рынок природного газа Казахстана реализует характерную для монопольных типов рыночных структур, модель «главного покупателя». На начальной стадии формирования находятся рынки Армении и Киргизии, которые имеют все признаки монопольной структуры. Российский рынок природного газа соответствует монопольной конкуренции, где, наряду с ведущим игроком действуют (в ограниченных рамках) независимые организации.

При этом, во всех странах ЕАЭС прослеживается высокая степень государственного вмешательства в функционирование газовых рынков. Конкуренция недостаточна развита, действие высоких барьеров для входа на рынок новых игроков и другие сдерживающие факторы создают дополнительные сложности в гармонизации законодательств стран ЕАЭС. Регулирование цен на природный газ в большинстве своем зависит от социально-экономических и политических целей национальных правительств ЕАЭС и отличается методологией их расчета. Однако в Договоре о ЕАЭС отражено стремление государств-участников к достижению равнодоходных цен газ. Вместе с тем, по мере развития рыночных отношений и интеграции стран ЕАЭС, равнодоходность может быть достигнута любым из известных способов ценообразования, в особенности, когда цены на нефть стремятся к низкому уровню [6].

Кроме того, важным фактором для прозрачного ценообразования, обеспечения и развития конкуренции является создание биржевой торговли газом, которая предполагает организованную торговлю. Достаточно новым этапом в развитии ЕАЭС является создание газовой биржи. Однако российский опыт может стать примером в осуществлении биржевых торгов газом, в частности газовая секция Санкт-Петербургской международной товарно-сырьевой биржи заработала в 2014 г. и к 2018 г. биржа сумела увеличить торговлю газом, достигнув 15,134 млрд. куб. м [3].

Вместе с тем, создание общего рынка газа Союза может сдерживаться существующими разногласиями во взаимоотношениях партнеров по ЕАЭС на двустороннем уровне - между Россией как основным поставщиком газа и странами потребителями российского газа [10].

С целью разрешения текущих споров по формированию общего газового рынка ЕАЭС, государствам-участникам необходимо создать модель хозяйственного механизма на основе соотношения сил и интересов стран, которая бы включала структуру, перечень компетенций регулятора общего рынка и его роль в общей системе органов ЕАЭС, в том числе подходы к ценообразованию на газ, порядок доступа к ГТС и др. [10].

\section{Выводы}

Несмотря на то, что за последние 25 лет на евразийском пространстве были проведены многочисленные интеграционные процессы, ЕАЭС является наиболее эффективной инициативой с целью восстановления экономических и энергетических связей. Фактически Россия является главным инициатором в создании Союза и играет ведущую роль в углублении региональной интеграции.

Учитывая, что топливно-энергетические комплексы десятилетиями формировались как единая система энергоснабжения всего Советского Союза, создание общего рынка газа на базе ЕАЭС позволит странам эффективно преодолеть существующие барьеры, а также достичь основной цели - обеспечение энергетической независимости и экономической безопасности стран-членов ЕАЭС, которая предусматривает освоение новых месторождений, их переработку, транспортировку на экспорт, а также расширение транзитного потенциала.

Кроме того, можно выделить следующие основные причины процесса формирования об- 
щего рынка газа стран-членов ЕАЭС:

1) газ сегодня является прибыльной статьей экспорта государств-членов ЕАЭС, гарантированные доходы от которого можно инвестировать в развитие газовой инфраструктуры;

2) добыча и транспортировка природного газа стимулируют развитие и объединение смежных отраслей экономики стран ЕАЭС, в частности производство труб и транспортно-логистического комплекса;

3) специфика продукции газового сектора неразрывно связана от колебаний мировой конъюнктуры;

4) конкурентоспособность природного газа за последние годы возросла - важно подчеркнуть, сравнительную надежность его сырьевой базы, высокую технологичность и благоприятные экологические свойства в сравнении с другими видами топлива;

5) распад интегрированных систем энергоснабжения - ЕСГ и Единой энергетической системы, которые создавались с учетом интересов всех регионов б.СССР, отрицательно сказался на эффективности энергообеспечения стран СНГ.

6) интеграция всего энергетического сек- тора ЕАЭС предотвратит проникновение на внутренний рынок западных энергетических компаний, угрожающее экономическому суверенитету стран-участниц Союза.

Первые четыре тезиса не вызывают сомнений. Что касается пятого тезиса, здесь необходимо указать на то, что распад вышеназванных систем привел к снижению ввоза топливно-энергетических ресурсов из России в СНГ, что в свою очередь вызвало рост социальной напряженности, политической нестабильности, усиление миграционных потоков и др. Однако этот процесс меньше всего коснулся природного газа - его доля в общем объеме импорта энергоресурсов из России увеличилась. Роль газовой отрасли в интеграционном процессе стала определяющей [4].

Последний тезис о необходимости сырьевой направленности интеграционных процессов ЕАЭС обусловлен тем, что на сегодняшний день ни одна отрасль не пользуется такой заинтересованностью экономическими и политическими кругами Запада, как топливно-энергетический комплекс ЕАЭС.

\section{Библиографический список}

1. Договор о Евразийском экономическом союзе от 29.05.2014. URL: https://docs.eaeunion.org/docs/ruru/0023611/itia_05062014_doc.pdf (дата обращения: 12.03.2020).

2. Аллаярова Н.И. Анализ задач и проблем, связанных с формированием общего рынка газа Евразийского экономического союза // Экономические науки. 2020. № 2 (183). С. 107-113. DOI: 10.14451/1.183107

3. Аллаярова Н.И. Вектор развития биржевой торговли в условиях формирования общего рынка газа Евразийского экономического союза // Сборник научных трудов участников VI Всероссийской научно-практической конференции с международным участием. МГУ им. Ломоносова. 2019. С. 30-35. URL: https://www. elibrary.ru/item.asp?id=41152876 (дата обращения: 12.03 .2020 ).

4. Бесчинский А.А, Боксерман Ю.И., Брагинский О.Б., Брянских В.Е., Макарова Т.Е., Маргулов Г.Д. Энергетика и общество: Роль газовой промышленности и интеграции стран СНГ. Москва: Газоил пресс, 1998. С. 11-25.

5. Golam M., Monowar M. Eurasian Economic Union: Evolution, challenges and possible future directions // Journal of Eurasian Studies. 2018. 9 (2). P. 163-172. URL: doi.org/10.1016/j.euras.2018.05.001 (дата обращения: 17.03.2020).

6. Еремин С.В. Рынки природного газа в условиях международной экономической интеграции: направления трансформации, ключевые факторы и вызовы: дисс. ... д.э.н.: 08.00.14. Москва, 2018. С. 222-240.

7. Коломейцева А.А. Проблемы и перспективы взаимоотношений России и стран СНГ на рынке газа: дисс. ... к.э.н.: 08.00.14. Москва, 2017. С. 13-21.

8. Коробцов Е.В. Отраслевые и институциональные факторы регулирования регионального рынка газа: дисс. ... к.э.н.: 08.00.05. Белгород, 2012. С. 19-99.

9. Пьянов С.А. Региональная экономическая интеграция в современных условиях: перспективы развития ЕАЭС: дисс. ... к.э.н.: 08.00.14. Москва, 2017. С. 57-117.

10. Ткаченко М.Ф., Аллаярова Н.И. Тенденции и потенциал формирования общего рынка газа в ЕАЭС // Вестник Российского университета дружбы народов. Серия: Экономика. 2020. Т. 27. № 4. С.638-648. 
11. Доклад «О состоянии взаимной торговли между государствами - членами Евразийского экономического союза в 2015-2016 годах» URL: http://www.eurasiancommission.org/ru/act/integr_i_makroec/dep_stat/ tradestat/analytics/Documents/report/Report_2015-2016.pdf (дата обращения: 16.03.2020).

12. Правовой портал Евразийской экономической комиссии URL: https:/docs.eaeunion.org/ (дата обращения: 15.03.2020). 